\title{
The Birds and the Bees: Do Puerto Rican Mothers and Daughters Talk about Sex?
}

\author{
Wanda I. Figueroa-Cosme ${ }^{1 *}$, Christine Miranda-Díaz ${ }^{1}$, Nanet M. Lopez-Cordova ${ }^{2}$, Jose A. Capriles ${ }^{3}$, Carmen \\ N. Velez ${ }^{3}$, Lydia E. Santiago ${ }^{4}$, Carmen Zorrilla ${ }^{4}$ \\ ${ }^{1}$ Universidad Central del Caribe, School of Medicine, Bayamon, Puerto Rico, USA \\ ${ }^{2}$ Ponce School of Medicine, Ponce, Puerto Rico, USA \\ ${ }^{3}$ University of Puerto Rico, School of Public Health, San Juan, Puerto Rico, USA \\ ${ }^{4}$ UPR School of Medicine-CEMI, San Juan, Puerto Rico, USA
}

*Corresponding Author: Dr. Wanda I. Figueroa-Cosme, Central University of the Caribbean, School of Medicine, Clinical Research Center, PO Box 60-327, Bayamon, PR, USA, Tel: 7877878710; E-mail: wanda.figueroa@uccaribe.edu

Received: 19 October 2018; Accepted: 29 October 2018; Published: 09 November 2018

\begin{abstract}
Introduction: Effective communication skills that foster responsible sexual decisions are known to have the potential to reduce the risky adolescent sexual behavior. It is well understood that maternal communication is a key element in modifying the adolescent sexual behavior. The objective of this qualitative study was to explore if Puerto Rican mothers of adolescent girls have conversations about sexuality with their daughters and the content of such conversations.
\end{abstract}

Methods: A total 22 HIV-seropositive mothers and 22 HIV-seronegative mothers were enrolled. Six focus groups were conducted, sessions were transcribed ad-verbum and coded for specific topics. All qualitative analysis was incorporated into Atlas.ti.

Results: Participants in both groups had a similar average age (mean=41 years old); but, the HIV-seropositive mothers were more likely single, less educated and unemployed. Regarding having engaged in conversations about 
sexuality and the topics covered, however, there were no differences revealed among HIV-seropositive mothers and seronegative mothers. In both groups, mothers understood the importance of these conversations, but most said they were difficult and uncomfortable.

Conclusion: These findings reinforce the importance of communication between mothers and daughters for the prevention of STIs, HIV/AIDS, and teenage pregnancy in minority populations. Interventions are needed for mother and daughter to improve communication skills, communication about sexuality, and addressing prevention.

Keywords: Communication about sexuality; Qualitative research; Women living with HIV; Hispanics

\section{Introduction}

During an adolescent's developmental stage, their particular family directly influences their sexual development and socialization and plays a significant role in their sexual risk-taking behavior [1]. Some researchers have suggested that "familism", defined as attitudes, behaviors, and family structure operating within an extended family system, exerts the most important influence in the lives of Latinos [2]. Latino parents and their adolescents generally discuss cultural beliefs, values and convey messages of protection, and these talks are more often directed specifically towards the female adolescents. In fact, having these talks with their family has been associated with the adolescents' decision to abstain from or delay sexual involvement [3]. Robles and colleagues reported that Puerto Rican adolescents whose parents admitted having poor communication and little to no monitoring or control over them were three to four times more likely to engage in sexual activities at an earlier age than those whose parents had close bonds with them and maintained control of their households [4].

It has been well reported how parents play a significant role in the sexual development and behavior of their children [5]. Hutchison and colleagues (2003) have suggested five pathways that explain how parents influence the sexual behavior of their adolescents: 1) closeness, 2) monitoring, 3) modeling of sexual behaviors, 4) disapproval of adolescent sexual activity, and 5) sexual risk communication [7]. Most importantly, the quantity and quality of the parents' communication play a crucial role in the extent of the influence on their children. Effective communication skills that foster responsible sexual decisions are known to have the potential to reduce the risky adolescent sexual behavior. However, actually having these conversations about sexuality between parents and adolescents are often quite difficult for both [6]. Whether parents do or do not talk about sexuality and AIDS can greatly impact the adolescents' knowledge, beliefs, and behavior. But more specifically, regarding the quality of these conversations, Lefkowitz pointed out that parental judging of their adolescents' opinion may jeopardize any future communication between them [7].

The association between mothers and their adolescent daughters having an open and positive communication and the daughters having less frequent intercourse and fewer sexual partners has been previously described [6, 8], highlighting the mother's role as being especially influential with decreasing sexual risks in their daughters. It is 
well understood that maternal communication is a key element in modifying the adolescent sexual behavior. Some researchers have reported that adolescents admit discussing about sexual topics more often with their mothers than their fathers $[9,10]$, while mothers are reported as discussing about sexual topics more often with their daughters than their sons $[9,11]$. Given the importance of the mother's role in their adolescent's sexual education, they are responsible for developing the necessary skills in order to effectively communicate, supervise, and educate their adolescents, and especially their adolescent daughters, about risk behavior, including those associated with HIV acquisition $[8,12]$. However, to take on this task and talk openly about sexuality remains uncomfortable for many mothers; some reasons relate to the fact that these mothers grew up during a time when talking about sexuality was banned or had less exposure in the media [13]. Of particular concern are HIV-seropositive mothers on how well they assume the responsibility of deterring risky behavior in their adolescent daughters. To their disadvantage, these adolescent daughters are often exposed to the same risk environment that placed their mothers at risk [14]. In spite of many disadvantages, some HIV-seropositive mothers of adolescent daughters can definitely serve as agents of change.

Mother-daughter sexual communication as an interventional tool for HIV/AIDS risk reduction is something that should be further explored. The ongoing presence and bonding of the mother-daughter dyad is expected to be an effective risk reduction intervention and even more so than interventions provided by trained health professionals. This article discusses a qualitative study (using focus group methodology) that explored sexual communication between Puerto Rican HIV-seropositive and HIV-seronegative mothers and their adolescent daughters, particularly examining the process of knowledge transmission about HIV, sexually transmitted infections (STIs), risk reduction, and pregnancy prevention.

\section{Methods}

\subsection{Design}

All qualitative data in this study was collected by utilizing focus groups, defined as: "a means to obtain individual's perceptions in an area of interest in an open non-threatening environment in order to understand a specific topic" [15]. Key personnel (principal investigator, co-investigator, two research assistants) were trained by a specialist in focus groups in two separate sessions.

Taking into account that the ideal size of a focus group is six to eight participants when dealing with complex topics [15], and smaller groups are easier to recruit and host, we aimed for a total of six focus groups, each with a comfortable range of participants, to be conducted at three different recruitment sites in Puerto Rico. A designated focus group moderator was consistently in charge in all groups. All sessions were tape-recorded and transcribed adverbum for content analysis. Prior to data collection, a pilot focus group was performed in order to examine the content and the flow of the guiding questions. Results from the pilot group served to rearrange the order of the questions and to add a question regarding sexual abuse. 


\subsection{Participants}

All mothers over 21 years of age and able to consent, who had at least one daughter aged 12-17 years old and living in the same household were considered as eligible participants All participants enrolled were recruited from various ambulatory clinics located in Puerto Rico at the Universidad Central del Caribe School of Medicine (UCC-SoM), the Ponce School of Medicine (PSM), and the Center for Maternal-Infant Studies (CEMI, acronym in Spanish) at the University of Puerto Rico-Medical Sciences Campus (UPR-MSC). Mothers known to be HIV-seropositive attending these clinics were asked to participate in person, by phone or by mail. Mothers known to be HIV-seronegative were contacted at general and gynecology ambulatory clinics, and at community-based organizations (CBOs). Both groups were equally balanced, enrolling $22 \mathrm{HIV}$-seropositive mothers and $22 \mathrm{HIV}$-seronegative mothers.

\subsection{Sample selection}

A purposeful sample of 44 mothers (22 HIV-seropositive mothers and $22 \mathrm{HIV}$-seronegative mothers) was selected to accommodate a total of six focus groups, of six to ten participants each, to be conducted at three different recruitment sites of Puerto Rico. The eligible mothers were given an appointment to come to the clinic at a predetermined time and date, in order to participate in a one-day focus group session. After the focus group session, each mother received a stipend of $\$ 30$ as compensation for their time and to cover transportation and meal costs.

\subsection{Data collection}

A trained moderator conducted all focus groups in Spanish using the guiding questions, which consist of open-ended and probing questions. The moderator's guide was divided into the following topics (see Figure 1): introduction and warm up, introductory questions, knowledge about HIV, STIs and pregnancy prevention, sexual communication, feelings about sexual communication, and others questions. The HIV serostatus of the daughters was not addressed. All six focus groups, of six to ten participants each, conducted at three different sites, were tape-recorded and transcribed ad-verbum for content analysis. These conversations were coded for specific topics. The moderator and a research assistant observed each session and took notes of the discussion. After completing each focus group session, the moderator and research assistant discussed any observed trends in their responses. This study was approved by three IRBs at UCC-SoM, PSM, and UPR-MSC.

\subsection{Data analysis}

All qualitative data was incorporated into Atlas.ti version 5.2 to facilitate data analysis. Each transcript was reviewed with the tape-recorded interviews for accuracy. The researchers present in the focus group session conducted the analysis. Content analysis was done following a pre-established guide of coded topics. Descriptive statistics were used to evaluate the distribution of variables. Proportion comparison was evaluated with the Chisquare or Fisher's exact statistic where applicable. The significance level was set at a p-value of .05. All statistical procedures were done in SPSS v14.0. Data was analyzed on participant group characteristics, for each of the two groups based on the mothers' HIV serostatus. 


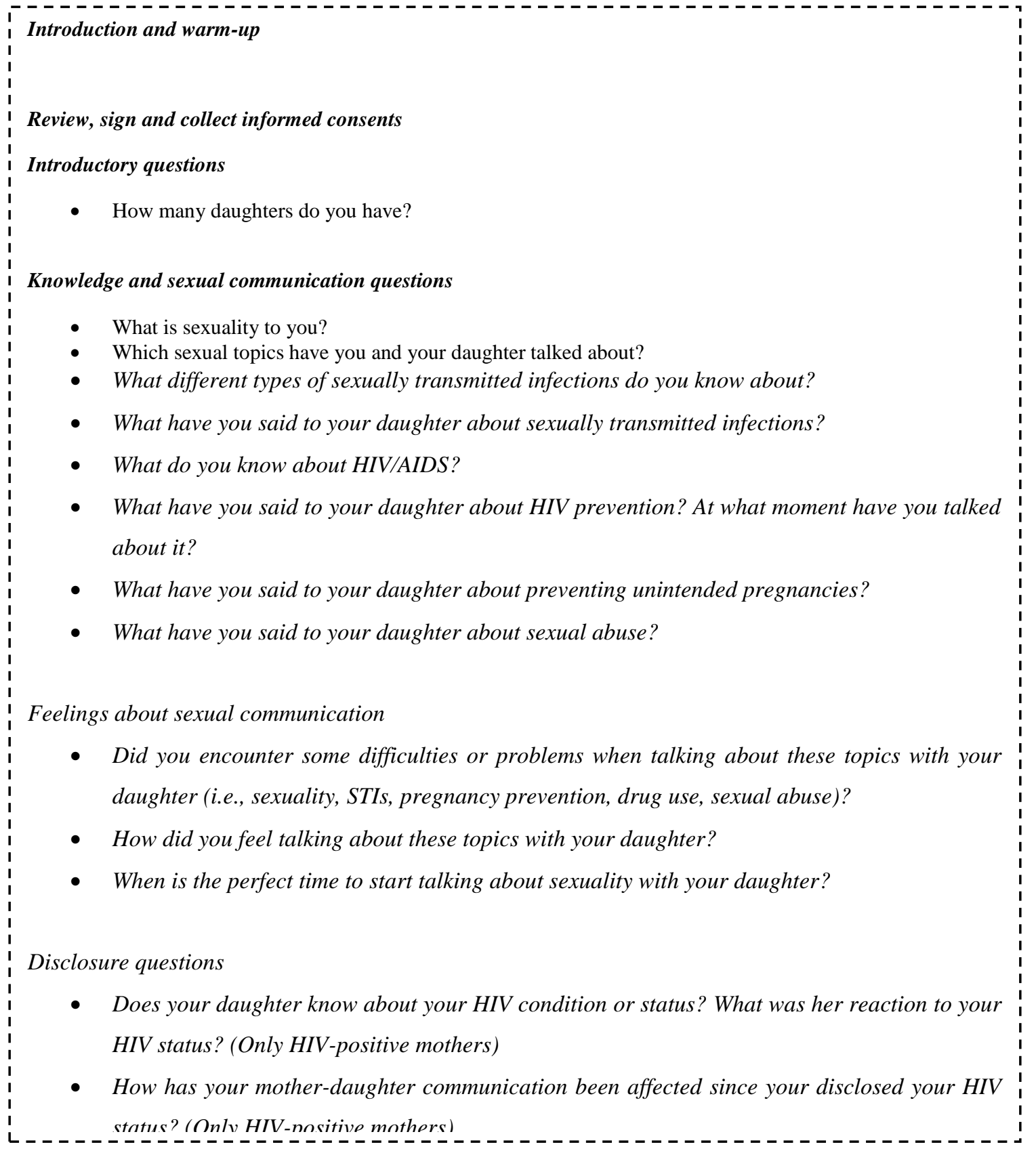

Figure 1: Moderator's guide, developed by the authors, for the conduction of focus groups.

\section{Results}

The socio-demographic characteristics of both participant groups of mothers, whether HIV-seropositive or HIVseronegative, are summarized in Table 1. The mean age for both groups was similar (mean=41 years old). Half of the HIV-seronegative mothers reported a live-in partner, whereas $31.8 \%$ of the HIV-seropositive mothers reported the same. Sixty-eight percent of the participants reported having 3 or more children. The percentage of mothers with 12 years of education or higher was as follows: $56.5 \%$ for HIV-seropositive mothers and $89.5 \%$ of HIVseronegative mothers, resulting in a statistically significant difference. Twenty-nine percent of the mothers reported 
monthly incomes lower than $\$ 300$ and $70 \%$ reported less than $\$ 900$. Most of the mothers (70.5\%) resulted in the Federal poverty level based on family composition and monthly income. Among those under the poverty level, 95.0\% were HIV-seropositive mothers and $60 \%$ were HIV-seronegative mothers, also statistically different. The principal source of health care insurance was Puerto Rico's government insurance, known as Mi Salud; $54.4 \%$ had the government's health insurance plan and $33.3 \%$ had private insurance.

\begin{tabular}{|c|c|c|c|c|c|}
\hline \multirow[t]{2}{*}{ Variable } & \multicolumn{2}{|c|}{$\begin{array}{l}\text { HIV-seropositive } \\
\text { mothers }(\mathrm{N}=22)\end{array}$} & \multicolumn{2}{|c|}{$\begin{array}{l}\text { HIV-seronegative } \\
\text { mothers }(\mathrm{N}=22)\end{array}$} & \multirow[t]{2}{*}{$p($ value $)$} \\
\hline & $\mathbf{n}$ & $\%$ & $\mathbf{n}$ & $\%$ & \\
\hline Age & & & & & 0.423 \\
\hline$<30$ & 3 & 13.6 & 2 & 9.1 & \\
\hline $31-40$ & 7 & 31.8 & 7 & 31.8 & \\
\hline $41-49$ & 8 & 36.4 & 12 & 54.5 & \\
\hline$\geq 50$ & 4 & 18.2 & 1 & 4.5 & \\
\hline Education & & & & & $0.019 *$ \\
\hline Less than $12^{\text {th }}$ grade & 10 & 43.5 & 2 & 10.5 & \\
\hline $12^{\text {th }}$ grade or higher & 13 & 56.5 & 17 & 89.5 & \\
\hline Employment status & & & & & $0.000 *$ \\
\hline Non-Employee & 18 & 85.7 & 3 & 13.6 & \\
\hline Employee & 3 & 14.3 & 19 & 86.4 & \\
\hline Have partner & & & & & 0.220 \\
\hline No & 15 & 68.2 & 11 & 50.0 & \\
\hline Yes & 7 & 31.8 & 11 & 50.0 & \\
\hline Monthly income & & & & & $0.007 *$ \\
\hline Less than $\$ 300.00$ & 11 & 50.0 & 2 & 9.1 & \\
\hline$\$ 301.00-\$ 600.00$ & 6 & 27.3 & 4 & 18.2 & \\
\hline$\$ 601.00-\$ 900.00$ & 2 & 9.1 & 6 & 27.3 & \\
\hline$\$ 901.00-\$ 1,200.00$ & 2 & 9.1 & 2 & 9.1 & \\
\hline More than $1,201.00$ & 1 & 4.5 & 8 & 36.4 & \\
\hline Number of persons in the household & & & & & 0.697 \\
\hline$<3$ & 13 & 54.2 & 12 & 60.0 & \\
\hline$\geq 4$ & 11 & 45.8 & 8 & 40.0 & \\
\hline Number of children & & & & & 0.517 \\
\hline$<2$ & 6 & 27.3 & 8 & 36.4 & \\
\hline$\geq 3$ & 16 & 72.2 & 14 & 63.3 & \\
\hline Health insurance & & & & & \\
\hline
\end{tabular}




\begin{tabular}{|l|l|l|l|l|l|}
\hline Public & 18 & 72.0 & 7 & 36.8 & $0.001^{*}$ \\
\hline Private & 1 & 4.8 & 13 & 61.9 & $0.000^{*}$ \\
\hline Illicit drug use & & & & & $0.002^{*}$ \\
\hline No & 13 & 54.2 & 19 & 95.0 & \\
\hline Yes & 11 & 45.8 & 1 & 5.0 & \\
\hline
\end{tabular}

*Pearson Chi-Square. *p< 0.05

Table 1: Socio-demographic characteristics of HIV-seropositive mothers and HIV-seronegative mothers.

The focus group sessions data was coded and the 11 topics were organized to differentiate the research findings based on the perceptions by mothers from the HIV-seropositive and the HIV-seronegative group. The topics were regarding the mothers' knowledge about STI, HIV/AIDS and pregnancy prevention, and sexual-based communications between mothers and daughters regarding prevention of risky sexual behaviors. The issues on adolescent daughters' self-esteem and peer pressure brought up by the mothers were not included in the guiding questions and were coded as other topics.

\subsection{Mothers' definition of sexuality}

In a general sense, both groups of mothers had the same definition of sexuality. For HIV-seropositive mothers, the definition of sexuality was more related to the anatomical difference between genders, the enactment of the sexual act, and the feelings between two individuals. HIV-seropositive mothers expressed that sexuality was never discussed during their adolescent years because it was considered taboo. One of the HIV-seropositive mothers admitted that sexual education cannot be delegated to the government, the church or to a teacher. Another HIVseropositive mother shared her experience of sitting with her children and talking about all kinds of drugs and paraphernalia because she did not want her children to be involved in that situation at an early age.

“When I was a little girl I was never oriented about sexuality, in my house, it was considered a taboo." (HIVseropositive mother)

For HIV-seronegative mothers, the definition of sexuality was broader, which included impulse control and physical emotions, sexually transmitted diseases and how to prevent them, and the use of oral contraceptives to prevent unintended pregnancy. Some of the HIV-seronegative mothers stated that "sex was a natural thing". One HIVseronegative mother expressed that "sexuality is a physical and thoughtful expression of feelings that should occur only within marriage". Another mother explained that she talked with her daughter about the religious part of sexuality. Some HIV-seronegative mothers mentioned that it is easier to talk about sexuality to their daughters because they are the same gender. For them, talking about sexuality to their daughters is important because they did not want their daughters to live the same way that they did during their adolescent years. For this group also, sexuality was considered a taboo subject during their adolescence. One HIV-seronegative mother said she talked to 
her daughter about sexuality when she started her menstruation. Another mother said that she used videos, TV programs and reggaeton music to educate her daughters.

"I think that sexuality is an expression of every person or every human being and it is attached to many things: the way we were raised, our thoughts, our fears, the prejudices we have and the knowledge. All of this is sexuality, but it is an expression." (HIV-seronegative mother)

\subsection{Mothers' discussion about sex topics}

All mothers talked to their adolescent daughters about menstruation, sexually transmitted diseases, oral, anal, and vaginal sex, how to protect themselves, about safe sex and prevention of sexually transmitted disease, condoms, sexual development, physical changes, pregnancy prevention, and abstinence.

"I said to my daughter that she will go through changes in her body, that these changes are normal and that there will be physical changes that she will become used to it. I explained that every woman goes through these changes. I also explained to her that emotional changes will occur as well." (HIV-seropositive mother)

"The only fulfillment that I will have in my life is that I tell her what is right." (HIV-seronegative mother)

\subsection{Mothers' knowledge about sexually transmitted infections}

The majority of both groups of mothers are concerned about sexually transmitted infections. One mother mentioned, "not all of the sexually transmitted infections have a cure". Another participant expressed that condoms are used to prevent pregnancy as well as these diseases. Some of the mothers spoke about the importance of protecting themselves not only for vaginal sex but for oral and anal sex. One mother stated it is the responsibility of both partners to protect themselves.

"Mom, is having sexual intercourse bad? I tell her: no, my love, it is the best thing in the world, it is something pleasant, as long as you have the right age, you know what you are doing, you know what it leads to, not only AIDS, there are other diseases, which are venereal diseases, emotional diseases..." (HIV-seronegative mother)

"The one that sleeps with you, slept with another, this other person slept with another, that other person slept with another and when you come to realize, it is a chain." (HIV-seronegative mother)

\subsection{Mothers' knowledge about HIV}

Both groups of mothers have knowledge about HIV infection and AIDS. One HIV-seropositive mother referred to HIV as "a pandemic because it has been spread around the world". Most mothers know that HIV is transmitted by a virus through humans' corporal fluids, that it affects the immune system and that people die from complications of this disease. HIV-seropositive mothers did express that this disease has no cure; however, it's treatable and a person 
can live with it. They also talked about several modes of transmission of HIV, such as sexual contact, needle sharing, direct contact with blood and tattoos. One mother shared her personal experience of acquiring the disease because she did not practice safe sex. Another mother said she acquired the disease by sharing needles. Some HIVseropositive mothers perceived this infection as a new opportunity to allow them to see the world differently. Another HIV-seropositive mother expressed her feelings of being ashamed.

"A lot of people think that HIV can be acquired by giving a hug to a person, giving a kiss. Sometimes I have encountered some people that tell me: I don't dare to give you a hug, I might get infected". (HIV-seropositive mother)

\subsection{Pregnancy prevention}

Both groups of mothers spoke to their daughters about the responsibilities and the possible consequences of having sexual intercourse at an earlier age. HIV-seropositive mothers talked to their adolescent daughters about protecting themselves against unintended pregnancy. Some mothers used as examples the experiences of other known adolescents that had children at a younger age, emphasizing the responsibilities they need to face and all the things they have to give up. Other mothers used their own experience as a way to give importance to the need for prevention, even though they expressed difficulty in discussing certain sexual topics with their adolescent daughters. HIV-seronegative mothers emphasized more that abstinence is the only way to prevent pregnancy; however, if sexual intercourse occurs they should use oral contraceptives, natural family planning, and condoms.

“... and now she have a baby, that is what happens if you get pregnant as a young girl, you will not be able to do the things that you enjoy right now; see how your friend has been affected and she does not have someone to take care of her baby.." (HIV-seropositive mother)

"It will be great if you delay sexual intercourse. But if you become sexually active, use all possible protections because none are always safe. You can get pregnant even if you use condoms or the pill." (HIV-seronegative mother)

\subsection{Sexual abuse}

Some of the mothers taught their daughters to not allow other people to touch their genital areas and that sexual abuse occurs by force. Some of them mentioned telling their daughters not to sit in someone else's lap, including their father or another male relative. One mother said she taught her daughter to defend herself if she is forced to have sexual intercourse. A few HIV-seronegative mothers shared that they experienced sexual abuse. Some emphasized that no one should be trusted, including relatives and family members. One mother described her reactions to her first sexual experience without consent. Another HIV-seronegative mother mentioned she is still trying to recover from her experience. On the other hand, some mothers did not talk about sexual abuse at all. 
"We can no longer think trustingly, someone can seem to be a good person but we cannot be sure. Nowadays, we cannot trust our grandfather, father, stepfather or any other person. We have to be careful." (HIV-seropositive mother)

"I always tell my daughter that there are the two kinds of sexual abuse: by force and those who do it in a loving way, get you involved, saying how pretty you are, just to have sex with you. It might be a relative or someone you trust, they don't show their true intentions" (HIV-seronegative mother)

\subsection{Communication barriers}

All mothers indicated they felt comfortable talking about many other topics with their daughters, but sexuality is a hard topic. Several HIV-seropositive mothers specifically mentioned feeling uncomfortable and shameful when talking to their daughters and how difficult it is. A few of the HIV-seropositive mothers indicated that they did not know how to answer their daughters' questions and did not know how to start a conversation about sexuality. Others felt uncomfortable letting their daughter know about their past sexual life. Most of the HIV-seronegative mothers expressed not feeling comfortable talking about sexuality because when they grew up no one talked to them about it; sex was considered a taboo. One mother mentioned how hard it is to maintain an open conversation with her children without judging her actions.

"I understand that the greatest difficulty is communication; that is, to maintain an open channel for communication. In my case, it has been learning to listen without judging. "

\subsection{Right age to talk about sex}

A topic that raised some controversy was 'when is the right age to talk about sex'. The majority of HIV-seropositive mothers indicated that it is important to talk about sex during their childhood years. Others mentioned that is better when they are curious. One mother mentioned that is better when they reach adolescence. However, most HIVseronegative mothers agreed that there is no specific age to start talking about sexuality. One mother expressed that it is best to start talking when they ask questions about it, no matter what at the age they are, but to answer according to their mental capacity.

"As soon as they ask the first question, 10, 12, 13, 17, or 25 years... at their moment of curiosity. I am prepared to talk to her; I will not do the same as my Mom did, I had to learn about it from books."

\subsection{Mothers' disclosure of their HIV status}

Several HIV-seropositive mothers have not disclosed their HIV status to their children yet. Those HIV-seropositive mothers that have disclosed, reported that some daughters became angry or cried at first; other daughter became more sensitive and attentive, where they became involved in their mother's adherence to medications and in protecting them from getting sick. Some mothers indicated that after disclosure of their HIV serostatus, the trust and 
communication with their children improved. Several HIV-seropositive mothers talked about using their own experience as a means of promoting HIV prevention. One mother shared her feelings after she disclosed her HIV serostatus on television.

“Listen, you can't use my personal things because I have a disease that can be contagious. Her daughter said: Hey Mom, it sounds as if you have AIDS. That gave me pain in my soul! Because I had to tell her that indeed I have it. She started to cry".

"Once my daughter knew my HIV status, she told me that I can't get wet in the rain, when it's cold, to wear a jacket. They did not want me to get pneumonia, to get sick, to be in a hospital."

"That day... I felt free, like a free spirit... Now I say as the song 'the next day I woke up and I thought I was the President'... Wow... I have a million viruses in my body, but I felt like a millionaire with money. Nobody knew about my status and I testified on television about it. My neighbors asked if I was the one on TV, I said yes, they said they admired me. I thank the Lord."

\subsection{Daughters' Supervision}

Some mothers indicated that supervision and sexual education is the mother's responsibility, because the father may be absent or because adolescent daughters do not communicate openly with their fathers. Others expressed that daughters' supervision is the responsibility of both parents, no matter if they are separated or divorced. Some mothers reported that they supervise their daughters by using the cell phone, by knowing their friends, and the parents of their friends. Other mothers admitted they have problems disciplining their children. One HIVseronegative mother said that supervision is essential because they cannot be with them 24 hours a day. Some mentioned that is important to develop trust.

"The mother, there is no one like the mother." (HIV-seropositive mother)

\subsection{Other topics}

Both groups of mothers expressed their interest in participating in workshops that teach how to talk with adolescent daughters about sexuality. HIV-seropositive mothers preferred workshops about sexual orientation, disclosure, selfesteem, emotions, peers' rejection, and fear. They also mentioned mother-daughter trust and conflict management. HIV-seronegative mothers preferred topics about trust, respect and responsibility, learning to listen, and anger control/management. Other topics discussed that were not included in the original questions and were brought up by the participants included: stigma, self-esteem, and peer pressure.

"I felt ashamed; I was afraid everyone would find out that that I have it [HIV]. I wore sunglasses to hide. No one could ask me any question. I cried, and cried, and cried. I did not how to face this". (HIV-seropositive mother) 
"The immaturity of many girls with low self-esteem leads them to think that having a baby can solve their problems, without thinking about the consequences". (HIV-seronegative mother)

"At my daughter's school, peer pressure is a challenge."

\section{Discussion}

Mothers as active risk-reduction educators is a cost effective instrument and should be integrated into HIV intervention programs that target female adolescents. It is well known that mothers have a primary role in sexual communication $[6,10]$ and adolescents have reported that discussions about sexual topics are more often done with their mothers than their fathers $[9,10]$. Dancy states that empowering mothers will translate directly into enhancing their daughters' risk reduction behavior by cultivating knowledge, risk reduction skills, self-efficacy to refuse sex, and intention to refuse sex [16].

Most of the mothers in this qualitative study had completed 12 years of education or higher, but the HIV seropositive mothers are less educated and have to tend to use more alcohol and illicit drugs. Gallegos found that parents with higher levels of education had higher levels of sexual knowledge but did not necessarily communicate openly or were comfortable talking about sex [17]. Parents with higher education levels scored higher in HIV knowledge and facilitated more general communication between parents and adolescents. Role modeling by the mother and the immediate environment to which children and adolescents are exposed are very important and may influence positive or negative behaviors in the children $[18,19]$. It was described that parents with higher levels of education had higher levels of sexual knowledge but did not necessarily communicate openly or were comfortable talking about sex [17]. The efficacy of the parenting and communication skills among HIV-seropositive mothers and their daughters correlates, in part, to their socio-demographics characteristics. Researchers have found that mothers with HIV/AIDS tend to be of a minority race/ethnicity, of single status, poorly educated, with limited economic /social resources $[17,18]$ and with a history of illicit drug use $[14,19]$. In this study, the comparison between HIVseropositive mothers and HIV-seronegative mothers did reveal the HIV-seropositive mothers to be more likely single, less educated and unemployed.

Many published studies have found that the mother is the primary sexual communicator [7, 9, 20]. Some studies found that discussions by Latino mothers focused more on beliefs, values and giving advice and protective messages $[3,11]$. In this study, most mothers indicated they were in charge of their children's supervision and sexual education, mainly because the paternal figure was absent. Some studies reported that mothers admit being uncomfortable talking about sexuality with their adolescent daughters [13, 16]. Most mothers acknowledge its importance during adolescence but are not so willing to perform this activity [21]. Latino and Asian mothers exhibited the highest level of discomfort and less frequent communications [22]. This study found that both groups of mothers agreed that they feel uncomfortable talking with their daughter about sexuality. Although all mothers had talked about the majority of the sexual topics, some mentioned they could not find the appropriate words to 
communicate about sexuality, limiting an open and effective communication channel between them. According to Lefkowitz parent-adolescent communication about sexuality is often difficult for both parties [7]. A meta-analysis of 52 articles confirmed that communication of sexual topics are uncomfortable or embarrassing for parents and youth [23].

During the pilot testing of the guide questions, the topic of sexual abuse raised without having it as one of the guide questions, the reason for which was added. HIV-seropositive and HIV-seronegative mothers also brought their concerns about sexual abuse and how to talk about it with their daughters, revealing the importance of subsequently adding a question regarding sexual abuse in the guiding questions for the next focus groups. Sikkema found that people living with HIV are more likely than the general population to have experienced sexual abuse during childhood [23]. Those with a history of sexual abuse are also more likely to engage in the unprotected sexual behavior, which is the most common form of HIV transmission among women [24]. In addition, the psychological consequences of childhood sexual abuse, such as lower self-esteem, avoidance, and self-destructiveness are associated with risky sexual behavior. In our study, some mothers shared their experiences of sexual abuse. Both groups of mothers expressed they talked to their daughters about sexual abuse. During the focus group sessions, other topics related to adolescents' developmental stage emerged from the discussion (i.e. low self-esteem and peer pressure). A longitudinal study of seventh-grade students revealed that girls with higher self-esteem were more likely to remain virgin than those with lower self-esteem, who were three times more likely to have sexual intercourse [24]. Sexual communication with parents, particularly mothers, plays a protective role in safer sex behavior among adolescents; this protective effect is more pronounced for girls than boys [20].

Another important aspect that formed part of the focus group discussions was the mothers' experiences disclosing HIV serostatus to their children. Prior studies have found that HIV-seropositive mothers are less likely to disclose their HIV serostatus to their younger children; however, disclosure was more common with their female children [17]. According to Murphy after HIV serostatus disclosure, about half of the children reacted in a positive manner and mothers felt unburdened [20].

Also is known that overall, the findings from this study provide important information on the value of actively involving mothers in an interventional program for HIV risk-reduction. There is a need to equip and educate parents on different sexual and reproductive health issues [27]. Further investigations would be required to explore the development of trust between mothers and daughters, and the quality and quantity of the sexual communications. In addition, studies should incorporate the adolescents' feelings when talking with their mothers about sexual topics. Also important to consider in future studies are the cultural factors, such as generational taboo and stigma, which might impact the mothers' communication about sexuality with their children. It is very important to develop an adequate health service or counseling specifically suitable for this specific age group of children, mothers and/or adults, and investigate the role of parents in this process. 


\section{Acknowledgements}

This research was supported by NIH-NIMH Grant \#2R25MH083617-04 at UPR-MSC. Also, this effort was made possible by NIH grant \#G12RR-03035/8G12MD007583 and by grants from the National Center for Research Resources (U54RR026139-01A1) and the National Institute on Minority Health and Health Disparities (8U54MD007587-03).

We thank Ms. Maria del Mar Rodriguez and Mr. Daniel Ramos for their support with data collection and transcription of the focus groups. We would like to thank Dr. Annette Ramirez de Arellano, Dr. Silvia Rabionet, and Dr. Mary H. Mays for their revision of this manuscript.

The authors also wish to acknowledge the editorial services from Dr. Deana Hallman from the Puerto Rico Clinical and Translational Research Consortium, which are supported by the National Institute on Minority Health and Health Disparities of the National Institutes of Health under Award Number 2U54MD007587. The content is solely the responsibility of the authors and does not necessarily represent the official views of the National Institutes of Health.

\section{References}

1. Perrino T, Gonzalez-Suldevilla A, Pantin H, et al. The roles of families in adolescent HIV prevention: A review. Clin Child Fam Psychol Rev 3 (2000): 81-96.

2. Velez-Pastrana MC, Gonzalez-Rodriguez RA, Borges-Hernandez A. Family functioning and early onset of sexual intercourse in Latino adolescent. Adolesc 40 (2005): 777-791.

3. Romo LF, Lefkowitz ES, Sigman M, et al. A longitudinal study of maternal messages about dating and sexuality and their influence on Latino adolescents. J Adolesc Health 31 (2002): 59-69.

4. Robles RR, Matos TD, Reyes JC, et al. Correlates of early sexual activity among Hispanic children in middle adolescence. P R Health Sci J 26 (2007): 119-126.

5. Rupp R, Rosenthal SL. Parental influences on adolescent sexual behaviors. Adolesc Med State Art Rev 18 (2007): 460-470.

6. Hutchinson MK, Jemmott JB, Jemmott LS, et al. The role of mother-daughter sexual risk communication in reducing sexual risk behaviors among urban adolescent females: a prospective study. J Adolesc Health 33 (2003): 98-107.

7. Lefkowitz ES, Sigman M, Au TK. Helping mothers discuss sexuality and AIDS with adolescents. Child Dev 71 (2007): 1383-1394.

8. DeVore ER, Ginsburg KR. The protective effects of good parenting on adolescents. Curr Opin Pediatr 17 (2005): 460-465. 
9. DiIorio C, Kelley M, Honckeberry-Eaton M. Communication about sexual issues: mothers, fathers, and friends. J Adolesc Health 24 (1999): 181-189.

10. Miller KS, Levin ML, Whitaker DJ, et al. Patterns of condom use among adolescents: the impact of mother-adolescent communication. Am J Public Health 88 (1998): 1542-1544.

11. Kapungu CT, Baptiste D, Holmbeck G, et al. Beyond the "birds and the bees": gender differences in sexrelated communication among urban African American adolescents. Fam Process 49 (2010): 251-264.

12. Mbugua N. Factors inhibiting educated mothers in Kenya from giving meaningful sex-education to their daughters. Social Science Medicine 64 (2007): 1079-1089.

13. Aronowitz T, Todd E, Agbeshie, et al. Attitudes that affect the ability of African American preadolescent girls and their mothers to talk openly about sex. Issues Ment Health Nurs 28 (2007): 7-20.

14. Cederbaum JA, Hutchinson MK, Duan L, et al. Maternal HIV serostatus, mother-daughter sexual risk communication and adolescent HIV risk beliefs and intentions. AIDS Behav 17 (2013): 2540-2553.

15. Krueger RA, Casey MA. Focus groups, a practical guide for applied research. Thousand Oaks, CA: Sage Publications (2000).

16. Dancy BL, Crittenden KS, Talashek M. Mother's effectiveness as HIV risk reduction educators for adolescent daughters. J Health Care Poor Undeserved 17 (2006): 218-239.

17. Gallegos EC, Villarruel AM, Gomez MV, et al. Research brief: Sexual communication and knowledge among Mexican parents and their adolescent children. J Assoc Nurses AIDS Care 18 (2007): 28-34.

18. Figueroa-Cosme WI, Lopez-Cordova NM, Capriles-Quiros JA. Mothers of adolescent girls: comparing HIV+ and negative women. Ethn Dis 20 (2010): 127-130.

19. Figueroa-Cosme W, Miranda C, Fernandez D, et al. Gender differences in social and developmental factors affecting Puerto Rican early-adolescents. Bol Asoc Med P R 102 (2010): 35-44.

20. Murphy DA. HIV-seropositive mother's disclosure of their serostatus to their young children: a review. Clin Child Psychol Psychiatry 13 (2008): 105-122.

21. Atienzo EE, Walker DM, Campero L, et al. Parent-adolescent communication about sex in Morelos, Mexico: does it impact sexual behaviour? Eur J Contracept Reprod Health Care 14 (2009): 111-119.

22. Meneses LM, Orrell-Valente JK, Guendelman SR, et al. Racial/ethnic differences in mother-daughter communication about sex. J Adolesc Health 39 (2006): 128-131.

23. Sikkema KJ, Wilson PA, Hansen NB, et al. Effects of a coping intervention on transmission risk behavior among people living with HIV/AIDS and a history of childhood sexual abuse. J Acquir Immune Defic Syndr 47 (2008): 506-513.

24. Sumter S, Bokhorst C, Steinberg L, et al. The developmental pattern of resistance to peer influence in adolescence: will the teenager ever be able to resist? J Adolesc 32 (2009): 1009-1021.

25. Widman L, Choukas-Bradley S, Noar SM, et al. Parent-Adolescent Sexual Communication and Adolescent Safer Sex Behavior: A Meta-Analysis. JAMA Pediatr 170 (2016): 52-61. 
26. Palatnik A, Seidman DS. Survey of opinions of mothers and teenage daughters on sexual behavior and contraceptive: descriptive study and literature review. Int J Womens Health 4 (2012): 265-270.

27. Shiferaw K, Getahun F, Asres G. Assessment of adolescents' communication on sexual and reproductive health matters with parents and associated factors among secondary and preparatory schools' students in Debremarkos town, North West Ethiopia. Reprod Health 11 (2014): 2.

Citation: Wanda I. Figueroa-Cosme, Christine Miranda-Díaz, Nanet M. Lopez-Cordova, Jose A. Capriles, Carmen N. Velez, Lydia E. Santiago, Carmen Zorrilla. The birds and the bees: do Puerto Rican mothers and daughters talk about sex?. Archives of Clinical and Medical Case Reports 2 (2018): 190-205.

(C)
This article is an open access article distributed under the terms and conditions of the
Creative Commons Attribution (CC-BY) license 4.0 